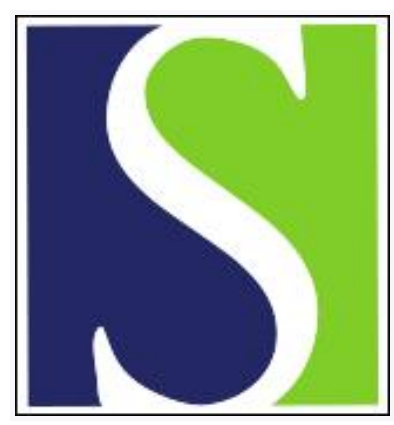

Scand J Work Environ Health 2006;32(2):160-167

https://doi.org/10.5271/sjweh.992

Issue date: 30 Apr 2006

\title{
Preventing injury, illness and disability at work
}

by Frank J, Cullen K; Institute for Work \& Health Ad Hoc Working Group

Affiliation: ClHR Institute of Population and Public Health, Suite 207-L, Banting Building, University of Toronto, 100 College St, Toronto, ON M5G 1L9, Canada. john.frank@utoronto.ca

Key terms: disability; discussion paper; effectiveness; illness; injury; intervention; occupational health; occupational safety; occupational safety and health; prevention; primary prevention; secondary prevention; work; workplace injury

This article in PubMed: www.ncbi.nlm.nih.gov/pubmed/16680387 


\title{
Preventing injury, illness and disability at work
}

\author{
by John Frank, MD, ${ }^{1,2,3}$ Kim Cullen, MSc, ${ }^{1}$ Institute for Work \& Health Ad Hoc Working Group ${ }^{4}$
}

\begin{abstract}
Frank J, Cullen K, Institute for Work \& Health Ad Hoc Working Group. Preventing injury, illness and disability at work. Scand J Work Environ Health 2006;32(2):160-167.

This discussion paper is intended to start a dialogue about prevention among those who are interested in making workplaces safer and healthier. The following four key themes are presented to build a framework for further discussion and activity: theme 1 - with multiple causes for workplace injury, illness, and disability, preventing these problems requires multiple solutions, operating in synergy; theme 2 - efforts to reduce workplace injury, illness, and disability must build on both primary and secondary prevention approaches, merging these to create a more effective strategy; theme 3 - before which strategies work and which do not can be agreed upon, a shared understanding is needed of how the effectiveness of occupational health interventions should be evaluated; and theme 4 - building relationships between those who do research and those who use research knowledge is important if relevant research is to be produced that is readily taken up and applied to improve occupational health and safety.
\end{abstract}

Key terms disability; effectiveness; intervention; occupational health and safety; primary prevention; secondary prevention; workplace injury.

Historically, occupational health and safety (OHS) programs have been directed towards workplace safety management and towards reducing workers' exposures to chemical and physical hazards (1). But after several decades of concentrated effort by researchers, policy makers, unions, and employers, the decline in the rates of workplace injuries is decelerating, and long absences from work persist after injury (2-4).

There is now a consensus from leading OHS researchers that workplace injury and disability are related to a complex set of risk factors, including physicalergonomic, psychosocial, and work-organizational factors (5-7). There is also agreement that, in many cases, such injuries can be prevented if certain policies, procedures, and practices are adopted (8-10).

This paper is intended to begin a dialogue about prevention among all those interested in making workplaces safer and healthier by building a framework for further discussion and, more importantly, activity.

\section{Four key themes for discussion}

We have identified the following four key themes which should guide discussion:

Theme 1. There are multiple causes of current workplace injuries, illnesses, and disabilities; preventing these causes requires multiple solutions, operating in synergy.

Theme 2. An optimal effort to reduce workplace injuries, illnesses, and disabilities must build on the strengths of traditional primary and secondary prevention approaches, merging these to create a more-effective strategy.

Theme 3. Before it can be agreed upon which prevention strategies work and which do not, a shared understanding of how the effectiveness of occupational health and safety interventions should be evaluated is needed.

1 Institute for Work \& Health, Toronto, Canada.

2 University of Toronto, Toronto, Canada.

3 Canadian Institutes of Health Research - Institute of Population and Public Health, University of Toronto, Toronto, Canada.

4 Members of the Institute for Work \& Health Ad Hoc Working Group: Curtis Breslin, PhD; Donald Cole, MD ; Pierre Côté, PhD; Renée-Louise Franche, PhD ; Cameron Mustard, PhD; Rhoda Reardon, OT ; Harry Shannon, PhD; Sandra Sinclair, MSc.

Correspondence to: John Frank, CIHR Institute of Population and Public Health, Suite 207-L, Banting Building, University of Toronto, 100 College St, Toronto, ON M5G 1L9, Canada. [E-mail: john.frank@utoronto.ca] 
[Effectiveness can be defined as "the extent to which a specific intervention, procedure, regimen, or service, when deployed in the field, does what it is intended to do for a defined population [p 41]" (11).]

Theme 4. Stronger relationships must be built between those who do research and those who apply the knowledge gained so that relevant research is produced that is readily taken up and applied to improve occupational health and safety.

While we have emphasized musculoskeletal injuries in our examples, we think the principles of these themes also apply to other occupational illnesses and injuries.

\section{The time is right}

Why do we feel this is the right time to initiate a dialogue on the prevention of workplace injuries?

There is currently a renewed impetus for increased prevention activities in many jurisdictions (12). In Ontario, Canada's most populous province, for example, the Workplace Safety and Insurance Board has stated its continuing commitment to eliminate all workplace injuries and illnesses. Changes introduced through the Workplace Safety and Insurance Act (13) mean that the Board shifted its strict role of providing no-fault workplace insurance for employers and their workers to include injury and illness prevention as part of its mandate. Other jurisdictions also have strong prevention mandates, for example, the Workers Compensation Board of British Columbia regulates OHS standard compliance through routine inspection of workplaces (14).

OHS practitioners have moved beyond simply presenting workplaces with advice based on anecdotal evidence or lists of mandated rules established by regulators. Increasingly, they are seeking, and then sharing, interventions and strategies that have been proved effective using sound evaluative research. This apparent desire to evaluate their own products and services and to understand their impact better further demonstrates that stakeholders are ready to discuss prevention effectiveness.

Health and safety researchers are demonstrating a new awareness that simply "studying and publishing" falls short (15). Researchers-and those who fund their work-now recognize the importance, right from the start, of explicitly identifying methods for transferring research results to relevant audiences $(16,17)$. This increased focus on those who use research knowledge has also helped to inform the research agenda, stimulating researchers to ask questions that are more relevant from the user's perspective.

Finally, within the workplace itself, there are notable examples of employers and labor representatives eager to incorporate research knowledge into their decision making (16).

\section{Theme 1}

There are multiple causes of current workplace injuries, illnesses, and disabilities; preventing these causes requires multiple solutions, operating in synergy.

A study on low-back pain offers a clear example of how multiple causes contribute to workplace health problems. The researchers looked at possible leading indicators (risk factors) for new complaints of work-related low-back pain among workers at a Canadian automobile assembly plant (18). They found that both psychosocial factors (such as perceptions that the workplace was not socially supportive) and measured ergonomic exposures played a significant role in workers' risk of a new episode of low-back pain. The study showed that tackling only ergonomic physical factors or only psychosocial factors would almost certainly limit the impact of any preventive efforts.

If OHS preventive interventions are to be designed, implemented, and evaluated effectively, a fusion between stakeholder involvement and active intervention is important (19). It is also essential to evaluate the chosen intervention's impact on a range of outcomes reliably (20). This is the main reason such evaluations generally require the involvement of a mix of disciplines, including behavioral science (individual and organizational), epidemiology, biostatistics, clinical specialties, and economics.

One way to conceptualize workplace prevention initiatives is to identify settings (eg, workplace, health care), stakeholders (eg, insurers, workplace parties, health care providers), types of intervention (eg, behavioral, educational, ergonomic, health care) and stage of intervention (eg, primary versus secondary prevention). Figure 1 presents a cube diagram that attempts to conceptualize the multidimensionality of prevention interventions. Any OHS prevention policy or program can be slotted into at least one cell of the cube.

Most OHS practitioners consider two fundamental approaches to prevention, according to the stage of health addressed, before (primary) or after (secondary) the onset of injury, illness, or disability.

Primary prevention aims at reducing the risk of injury or illness before the event occurs (while the person is still healthy). This aim is generally accomplished by modifying factors known to increase risk by directly controlling a specific hazard or set of hazards, for example, increasing a worker's skills or modifying the work environment (5).

Secondary prevention occurs after injury or illness has occurred and aims at reducing long-term disability 


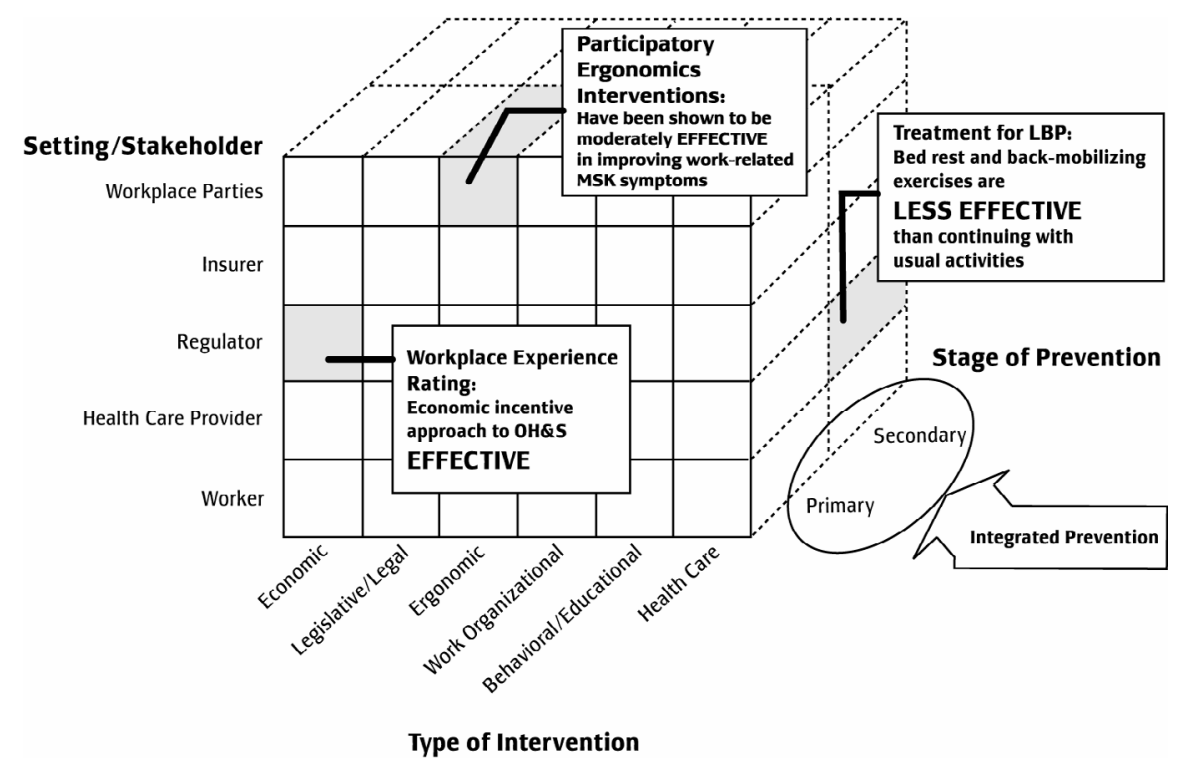

Figure 1. Ways of categorizing preventive interventions in occupational safety and health into three dimensions. Note: lists on each axis are exemplary only, not exhaustive. (MSK $=$ musculoskeletal, $\mathrm{LBP}=$ low-back pain, $\mathrm{OH} \& \mathrm{~S}=$ occupational health and safety) and the associated personal, social, and economic costs. Such interventions include improving the quality of care that workers receive or introducing appropriate disability management strategies. The latter includes the provision of suitably modified work to accommodate the worker until the disability improves or vocational retraining if the disability is permanent and incompatible with the worker's original job. Such interventions have a much lower success rate and are more costly when they are implemented more than 6 months' after the injury (6).

Secondary prevention is not restricted to work-related musculoskeletal disorders and injuries. Some toxic exposures in workplaces are currently best controlled by exposure reduction at the source (primary prevention), supplemented by biological monitoring of the levels of body burden absorbed (eg, lead exposure) or the degree of sensitization of the worker to the exposure (eg, noise-induced hearing loss). We will return to this idea below in theme 2 , when we consider the emerging case for integrated occupational prevention programs in workplaces.

In general, while primary prevention is clearly preferable to secondary prevention on ethical grounds, it is not always feasible. This lack of feasibility is especially true in areas in which the knowledge about the causation of injury, illness, or disability is limited. For example, when it comes to occupational low-back pain (the largest single cause of workers' compensation claims in many jurisdictions), we still have few proved primary preventive interventions, even though some ergonomic and work-organizational interventions are promising $(10,21)$. Yet we know a great deal about how to reduce disability and promote full recovery among workers who have already been injured, especially in terms of optimal health care practices and disability management policies at the workplace (22).

\section{Theme 2}

An optimal effort to reduce workplace injuries, illnesses, and disabilities must build on the strengths of traditional primary and secondary prevention approaches, merging these to create a more-effective strategy.

Many OHS experts are embracing the concept that a more holistic approach to primary and secondary prevention strategies makes sense. How can this change in perspective be explained?

The most common occupational injuries-soft-tissue sprains and strains, including low-back pain of mechanical origin and repetitive strain injuries of the upper limb-tend to recur over many years after their first onset. Such injuries are already so common in some workforces that most workers cannot benefit from true primary prevention because they have already had symptoms. The goal must then be to control the symptoms, reduce disability, and optimize function.

It has been shown in several settings that integrated, multipronged programs work best. These programs include ergonomic improvements in job design, toxic exposure control programs, modern disability management via workplace committees and multidisciplinary care teams, and, finally, an OHS cultural change in the workplace as a whole. When used together, these approaches contribute powerfully to both primary and secondary intervention in a synergistic way (23-25). These integrated OHS intervention programs can thus be said to contribute to overall disability prevention or control, acting at multiple stages before the disability becomes chronic or severe. 
Recently, Yassi et al (26) presented the logic behind integrating workplace resources across primary and secondary prevention approaches-a task which they described as "breaking down the solitudes". This proposal stemmed from the following observations:

- An effective primary prevention initiative that was ergonomic in nature resulted not only in fewer injuries (primary prevention) in a hospital setting, but also in unexpectedly shorter durations of lost time after injury (secondary prevention) (27).

- A comprehensive, hospital-based, return-to-work program for nursing personnel, which decreased time lost from work after injury in the targeted wards (secondary prevention), also resulted in an unexpected reduction in injury incidence (primary prevention) $(24,25)$.

In both of the previous studies, Yassi and her colleagues noted that the commitment of senior management and meaningful worker participation were crucial for the success of the programs. Synergistic injury prevention and disability management initiatives appear to make more efficient use of available resources (both personnel and financial) and should lead to more sustained improvements in workplace injury, illness, and disability outcomes.

A recent qualitative study from Quebec (28), examining return-to-work success after musculoskeletal injury in the electric and electronic sector, identified several key factors that facilitated return to work. One key to success was the integration of health and safety prevention activities and return-to-work programs. Injury investigations, examining the physical and organizational factors that led to the workplace injury, were useful when recommendations were made for job modifications to help the injured worker return to his or her regular job. The investigations also yielded corrective strategies to prevent similar injuries to other workers. Another effective approach was to use the same safety-oriented persons responsible for the prevention of musculoskeletal injuries to develop appropriate modified return-to-work programs for injured workers.

A people-oriented culture in the workplace is crucial to the success of integrated prevention and returnto-work programs. For example, Stock et al (28) found that, when management demonstrated a strong commitment to effective health and safety initiatives through their actions, workers believed their employers were genuinely concerned with their health and well-being, rather than simply being preoccupied with cost control. Studies have consistently found that this "people-first" commitment leads to open communication and trust between workers and their supervisors and predicts reductions in injuries and disability duration (23, 29-33).
Recognizing the multifactorial risk factors for musculoskeletal disorders, Cole and his colleagues (34) have developed and are testing a new framework for evaluating an integrated preventive intervention program within the office operations of a large Ontario newspaper. This framework provides stakeholders with strategies, objectives, and measurement tools to evaluate the effectiveness of comprehensive intervention programs on outcomes, including both injury incidence and long-term disability. While the researchers are optimistic that this framework will be useful in evaluating integrated interventions, it is still too early to draw conclusions about its effectiveness. [We discuss the evaluation of intervention effectiveness in theme 3.]

Despite the growing evidence that primary and secondary prevention strategies work best when they work together, some stakeholders are still structured—or mandated-to work only on primary prevention (traditional safety programs in the workplace) or secondary prevention (disability management programs). This is not an ideal situation, but it provides us with an obvious target for change.

\section{Theme 3}

Before it can be agreed upon which prevention strategies work and which do not, a shared understanding of how the effectiveness in occupational health and safety interventions should be evaluated is needed.

In order for a preventive strategy to be successful, we need reliable ways to measure and determine effectiveness. Only then can we be sure that reductions in adverse outcomes are the direct result of particular policies or programs. The major thrust of this theme will be to emphasize the importance of carefully evaluating the effectiveness of interventions and conducting these evaluations in an interdisciplinary fashion.

The best way to ensure that evidence-based interventions are used is to develop a partnership between those who produce knowledge through research or evaluation and those who use it. In many cases, however, researchers and decision makers are unable to understand each other's needs or even to communicate effectively. Lomas (35) says this situation is like "two people trying to assemble a jigsaw puzzle, each with half the pieces ... but each working in a separate room [p $1]^{\prime}$.

There are two critical junctures in the relationship between research producers or evaluators and decision makers. The first occurs before the decision to implement a program or policy; the second occurs after implementation, when the time comes to measure impact.

Before deciding whether to implement a new intervention (program, policy, or practice), decision makers 
may seek some kind of helpful tool or decision aide. One such tool is an expert critical review of available evidence that has been translated into an accessible format. Eventually, it becomes possible to produce regularly updated and user-friendly databases that efficiently summarize the best-quality evidence available on each major intervention option, for use by a wide variety of audiences. This strategy is already working for clinicians who seek best evidence on health care interventions (eg, the Cochrane Library, which can be accessed online at www.cochrane.org).

After implementation, a certain amount of time must pass before observers can determine whether or not the intervention has been effective. During this period, it is important to maintain close collaboration among the research users and the researchers or evaluators, who are trained to assess impact. Such an approach is more likely to produce a rigorous, relevant evaluation design. The evaluation strategy should be agreed upon a priori to provide answers to the users' key questions about the intervention.

This kind of multistep, before-and-after process is critical to ensure that appropriate prevention goals are achieved. One exciting example of this strategy comes from Yassi and her colleagues (36) in British Columbia. Using a collaborative problem-solving approach, researchers, workers, and managers identified problems and implemented evidence-based initiatives to improve the health and work conditions of health care workers. First, the collaborators conducted a needs assessment and then reviewed the scientific literature. The process also included stakeholder-focus groups and cost-benefit analyses. The researchers then used their data to develop best-practice guidelines. The project was so successful that all of the stakeholder parties have agreed to continue this collaboration and process to address ongoing OHS challenges in the health care sector.

When it comes to prevention, what do we mean by "evidence of effectiveness"? A major challenge to those involved in designing prevention strategies is obtaining the best possible evidence both before and after an intervention takes place. Researchers must be extremely careful in designing such interventions and also in how they collect, synthesize, and interpret data (19). Some important points to consider in evaluating intervention effectiveness follow.

Evaluating effectiveness takes time. A considerable amount of time must often pass before it is possible to determine, with certainty, whether an intervention has had any impact. Mere personal observation of effectiveness is not enough. For example, in programs to reduce asbestos exposure, it takes more than 20 years to see reductions in the rates of asbestos-related cancers and asbestosis. When it comes to implementing better re- turn-to-work policies, the lag times are shorter, but it can still take between 3 and 5 years before a reduction in long-term disability and its costs become apparent in a whole population. However, early leading indicators of impact may be noticed sooner. In the return-to-work example, reductions in the proportion of workers still receiving temporary disability compensation benefits 1 year after injury may be evident within a few years. In the asbestos example, documentation of reduced exposure levels is acceptable when we know, as in this case, that the exposure is causal for ill health.

Commonly accepted wisdom is not necessarily evidence. When it comes to prevention interventions, too often rigorous evaluations are not carried out to determine effectiveness. This oversight can result in the widespread adoption of ineffective interventions. For example, Saari (37) described a safety-poster campaign in a shipyard and reported that it was well-received by the workers. But careful comparisons with a control group found that the poster campaign had no actual effect on safety outcomes among shipyard workers. According to Saari, "If a careful evaluation of accidents had not been made, the campaign would have been promoted as an effective program [p 184]."

Evidence evaluators must possess a diverse skill set. Many disciplines are involved in evaluating the effectiveness of OHS interventions (eg, management sciences, organizational behavior, traditional social and behavioral sciences, epidemiology, biostatistics, ergonomics, biomechanics, and physiology). However, many researchers are not experienced in multidisciplinary teamwork. Thus some evaluations of new programs or policies are not well executed because the evaluating team is too narrowly based. Achieving multidisciplinary evaluations requires building closer long-term relationships among workplaces, regulators, insurers, other stakeholders, and researchers. [We return to this idea under theme 4.]

Real-world interventions cannot be properly evaluated in a laboratory. Many extraneous factors can influence OHS outcomes, which require complex evaluation approaches and study designs. This problem is further complicated by the fact that many such influential factors do not remain constant over the duration of a new program or policy implementation. For example, provincial (or national) worker compensation claim rates are affected over time by an array of factors, for example, business cycles and labor market phenomena, legislative and regulatory changes, evolving long-term sectoral shifts in workforce composition, and the nature of the economy, such as declining primary resource extraction and increasing service sectors $(3,4,38)$. 
Findings should be replicable. An important principle in science is replication. In many circumstances, we only have one high-quality study looking at a particular intervention, and we must rely on it as the best information available. But single studies may have flaws (or quirks) that are not obvious. Ideally, it is better to have corroborative evidence from at least one other independent study (conducted by others in a different setting). Many will remember the example from physics of the false promise of cold fusion. After the study by Fleishman et al (39) was reported, many others tried to replicate their results, but could not do so. It was thus generally agreed that the initial experiment was flawed.

Individual stakeholder agendas must not be allowed to influence evaluation results. There is a natural tendency in prevention evaluations-as in other aspects of occupational health and safety-for various vested interests to desire particular evaluation outcomes. This aspect underscores the need for high-quality evidence of effectiveness, which can withstand scientific peer review and legal scrutiny. For details, see the commentary on the ergonomic regulation hearings held in 2000 in the United States by the Occupational Safety and Health Administration (40).

Researchers and evaluators must do more than simply share results. They must also share an understanding of what does-and does not-constitute dependable, strong, and reliable results. Unfortunately, the strength of much prevention research available today is limitedreviews show that a large proportion of published studies (even those that have undergone peer review) are based on weak designs and inadequate data analysis. They are thus open to valid criticism and so are not especially helpful to decision makers and other stakeholders.

Fortunately, there are several excellent resources that offer guidance in critically appraising intervention research $(19,20,41,42)$. For workplace parties and OHS professionals seeking information and practical assistance, research advisors and consultants skilled in evaluation design will continue to be needed.

One must consider the ethical and economic impacts of intervention. In addition to the preceding considerations, before a prevention intervention is implemented, stakeholders should consider the ethical and economic impacts of existing evidence.

There is always the possibility that an apparently benign prevention program may have unanticipated neg- ative effects. For example, some researchers looking at experience ratings ${ }^{5}$ of workers compensation premiums have been concerned that business firms might attempt to hide cases of occupational injury and illness (43). One method to conceal such data would be to provide health care directly to the injured worker and thus bypass formal reporting to the workers' compensation system. Decision makers and stakeholders must be aware that an intervention can have this kind of unintended effect.

Each prevention option (including the "do nothingbusiness as usual" option) has pros and cons and affects costs. For the best use of available resources for prevention, existing evidence about these alternative programs, policies, and practices should be used to inform decision makers.

\section{Theme 4}

Stronger relationships must be built between those who do research and those who apply the knowledge gained so that relevant research is produced that is readily taken up and applied to improve occupational health and safety.

Research organizations and granting agencies are recognizing how essential it is that knowledge from scientific studies does not stop at publication $(15,44)$. They understand the value of knowledge transfer and exchange, a discipline that ensures that knowledge is transferred to the appropriate audiences in the form of compelling ideas or useful tools. At the same time, many decision-making organizations have recognized the need to be informed of prevention activities and are obtaining scientifically standardized reviews of existing research (known as systematic reviews).

The Canadian Health Services Research Foundation describes this situation as the "push-pull style" of knowledge brokering. It suggests that it is a stepping stone towards better, longer-term knowledge-brokering based on sustained relationship building between the producers and users of research knowledge.

When we consider the role of knowledge transfer in health outcomes, it is worth remembering that many diverse methods can effectively communicate the message to the intended audience. Buchbinder and her colleagues (45) used a multimedia back-education advertising campaign aimed at the general public in Australia to change attitudes and expectations about back pain. The results from the 2-year program were more scientifically based beliefs about back pain in the general population, improved knowledge and attitudes of health care practitioners (which appeared to influence their management

5 The process through which employer's workers' compensation insurance premiums are tied to their accident records (ie, higher accidents rates produce higher premiums the employer must pay). This process creates a financial incentive for employers to improve their workplace's health and safety through injury prevention. 
of back pain), and reduction in the compensation and disability costs related to back pain.

While these important seeds are finally being planted, we must take steps to tend and encourage the crop. For example, we must develop planned, multiyear programs of knowledge transfer and exchange that link OHS evaluative researchers and research users. These programs will yield research that is relevant and informed by user experience and produces knowledge that proceeds directly to uptake and application, and which results in improved decision making. Such an approach recognizes that research and decision making are part of a paired process, and that the greatest benefit comes from creating and exploiting multiple points of contact within long-term relationships.

\section{Next steps}

In this paper we have reviewed the types of preventive interventions in occupational safety and health, argued for more integration of primary and secondary prevention, suggested the need for shared understanding of what constitutes convincing evidence of effectiveness, and advocated for closer ties between OHS researchers, research users and decision makers. All of these strategies are like links in a chain-the chain from sound OHS research to effective policies, programs and practices. Any weak link may compromise the whole chain - but we believe that, together, these strategies can and will make a significant difference to workers' health.

\section{Acknowledgments}

This research was supported by a personal grant to the first author from the Canadian Institutes of Health Research.

The authors thank Glenn Pransky, PhD, Robert Spasoff, MD, Annalee Yassi, PhD, and Gary Franklin, MD for their review of the first draft of the manuscript. We thank Jane Brenneman Gibson for her ongoing communication with key OHS partners in Ontario and for her valuable feedback on the conceptualization and drafting of this manuscript. We also thank Evelyne Michaels for her substantive editorial contributions to this manuscript. Special thanks goes to Carol Holland for her help in designing the prevention cube figure.

\section{References}

1. Emmett EA. Occupational health and safety in national development- the case of Australia [review]. Scand J Work Environ Health. 1997;23:325-33.

2. Workplace Safety and Insurance Board. Statistical supplement to the 2000 Annual Report. Toronto: Workplace Safety and Insurance Board; 2000. p 1-32.
3. Ostry A. From chainsaws to keyboards: injury and industrial disease in British Columbia. In: Sullivan T, editor. Injury and the new world of work. Vancouver: UBC Press; 2000. p 27 45.

4. Mustard C, Cole D, Shannon H, Pole J, Sullivan T, Allingham $\mathrm{R}$, et al. Declining trends in work-related morbidity and disability 1993-1998: a comparison of survey estimates and compensation insurance claims. Am J Public Health. 2003; 93:1283-86.

5. Frank JW, Kerr MS, Brooker AS, DeMaio S, Maetzel A, Shannon HS, et al. Disability resulting from occupational low-back pain part I: what do we know about primary prevention? a review of the scientific evidence on prevention before disability begins. Spine. 1996;21:2908-17.

6. Frank JW, Brooker AS, DeMaio S, Kerr MS, Maetzel A, Shannon HS, et al. Disability resulting from occupational low-back pain part II: what do we know about secondary prevention? a review of the scientific evidence on prevention after disability begins. Spine. 1996;21:2918-29.

7. Krause N, Frank JW, Dasinger LK, Sullivan TJ, Sinclair SJ. Determinants of duration of disability and return-to-work after work-related injury and illness: challenges for future research. Am J Ind Med. 2001;40:464-84.

8. Fallentin N. Regulatory actions to prevent work-related musculoskeletal disorders - the use of research-based exposure limits [editorial]. Scand J Work Environ Health. 2003;29:24750.

9. Shannon HS, Mayr J, Haines T. Overview of the relationship between organizational and workplace factors and injury rates. Saf Sci. 1997;26:201-17.

10. Shannon HS, Robson LS, Sale JEM. Creating safer and healthier workplaces: role of organizational factors and job characteristics. Am J Ind Med. 2001;40:319-34

11. Last JM. A dictionary of epidemiology. Toronto: Oxford University Press; 1988.

12. Rosenstock L, Olenec C, Wagner GR. The national occupational research agenda: a model of broad stakeholder input into priority setting. Am J Public Health. 1998;88:353-6.

13. Government of Ontario. Workplace safety and insurance act, 1997. Toronto: Queen's Printer; 2000.

14. Workers' Compensation Board of British Columbia. Occupational health and safety regulation: core requirements. Vancouver: Workers' Compensation Board of British Columbia; 1998.

15. Hernberg S. Research, prevention and impact [editorial]. Scand J Work Environ Health. 1995;21:161-3.

16. Kramer DM, Cole DC. Sustained, intensive engagement to promote health and safety knowledge transfer to and utilization by workplaces. Sci Commun. 2003;25:56-82.

17. Kramer DM, Cole D, Leithwood K. Doing knowledge transfer: engaging management and labor with research on employee health and safety. Bull Sci Technol Soc. 2004;24:31630.

18. Kerr MS, Frank JW, Shannon HS, Norman RW, Wells RP, Neumann WP, et al. Biomechanical and psychosocial risk factors for low-back pain at work. Am J Public Health. 2001;91:1069-75.

19. Robson LS, Shannon HS, Goldenhar LM, Hale AR. Guide to evaluating the effectiveness of strategies for preventing work injuries: how to show whether a safety intervention really works. Cincinnati $(\mathrm{OH})$ : National Institute for Occupational Safety and Health; 2001. p i-121.

20. Shannon HS, Robson LS, Guastello SJ. Methodological criteria for evaluating occupational safety intervention research. 
Saf Sci. 1999;31:161-79.

21. Rivilis I, Van Eerd D, Cullen K, Cole D, Irvin E, Tyson J, Mahood Q. Effectiveness of participatory ergonomic interventions: a systematic review. Toronto: Institute for Work \& Health; 2005. Working Paper Series 300.

22. Frank J, Sinclair S, Hogg-Johnson S, Shannon HS, Bombardier C, Beaton D, et al. Preventing disability from workrelated low-back pain. Can Med Assoc J. 1998;158:1625-31.

23. Habeck RV, Hunt HA, VanTol B. Workplace factors associated with preventing and managing work disability. Rehabil Couns Bull. 1998;42:98-143.

24. Yassi A, Khokhar J, Tate R. The epidemiology of back injuries in nurses at a large Canadian tertiary care hospital: implications for prevention. Occup Med. 1995;45:215-21.

25. Yassi A, Tate R, Cooper JE, Snow C, Vallentyne S, Khokhar JB. Early intervention for back-injured nurses at a large Canadian tertiary care hospital: an evaluation of the effectiveness and cost benefits of a two-year pilot project. Occup Med. 1995;45:209-14.

26. Yassi A, Ostry A, Spiegel J. Injury prevention and return to work: breaking down the solitudes. In: Sullivan T, Frank J, editors. Preventing and managing injury and disability at work. London: Taylor \& Francis; 2003. p 75-86.

27. Ronald LA, Yassi A, Spiegel J, Tate RB, Tait D, Mozel MR. Effectiveness of installing overhead ceiling lifts. AAOHN J. 2002;50:120-7.

28. Stock S, Deguire S, Baril R, Durand M-J. Obstacles and factors facilitating return to work of workers with musculoskeletal disorders: summary of the report on the Quebec qualitative study in the electric and electronic sector of workready phase 1 . Montreal: Direction de la sante publique; 1999. p 1-17.

29. Amick BC, Habeck RV, Hunt A, Fossel AH, Chapin A, Keller $\mathrm{RB}$, et al. Measuring the impact of organizational behaviors on work disability prevention and management. J Occup Rehabil. 2000;10:21-38.

30. Amick BC, Habeck RV, Ossman J, Fossel AH, Keller R, Katz JN. Predictors of successful work role functioning after carpal tunnel release surgery. J Occup Environ Med. 2004;46:490500 .

31. Habeck RV, Leahy MJ, Hunt HA, Chan F, Welch EM. Employer factors related to workers' compensation claims and disability management. Rehabil Couns Bull. 1991;34:210-26.

32. Katz JN, Amick BC, Keller R, Fossel AH, Ossman J, Soucie $\mathrm{V}$, et al. Determinants of work absence following surgery for carpal tunnel syndrome. Am J Ind Med. 2005;47:120-30.

33. Ossman J, Amick BC, Habeck RV, Hunt A, Ramamurthy G,
Soucie V, et al. Management and employee agreement on reports of organizational policies and practices important in return to work following carpal tunnel surgery. J Occup Rehab. 2005;15:17-26.

34. Cole DC, Wells RP, Worksite Upper Extremity Group. Interventions for musculoskeletal disorders in computer-intense office work: a framework for evaluation. Work Stress. 2002;16:95-106.

35. Lomas J. Improving research dissemination and uptake in the health sector: beyond the sound of one hand clapping. Hamilton: Centre for Health Economics and Policy Analysis (CHEPA), McMaster University; 1997. p 1-45. Policy Commentary, Paper C97-1.

36. Yassi A, Ostry AS, Spiegel J, Walsh G, de Boer HM. A collaborative evidence-based approach to making healthcare a healthier place to work. Hosp Q. 2002;5:70-8.

37. Saari J. Safety interventions: international perspectives. In: Feyer AM, Williamson A editors. Occupational injury-risk, prevention and intervention. London: Taylor and Francis; 1998. p 179-95.

38. Gunderson M, Hyatt D. Workforce and workplace change: implications for injuries and compensation. In: Sullivan T ed. Injury and the new world of work. Vancouver: UBC Press; 2000. p 46-68.

39. Fleischmann M, Pons S, Hawkins M, Hoffman RJ. Measurement of gamma-rays from cold fusion. Nature. 1989;339:667.

40. Frank J, Lomax G. Public health action to control hazards: how good should the evidence be? Reflections on the OSHA ergonomics standard hearings. New Solutions. 2002;12:1725.

41. Goldenhar LM, Schulte PA. Methodological issues for intervention research in occupational health and safety. Am J Ind Med. 1996;29:289-94.

42. Goldenhar LM, Schulte PA. Intervention research in occupational health and safety. J Occup Med. 1994;36:763-75.

43. Ison TG. The significance of experience rating. Osgoode Hall Law J. 1986;24:723-42.

44. Reardon, R. Educational influentials: Keeping each other informed. Toronto: Institute for Work \& Health; 2003. In Focus 35[a], 1-2.

45. Buchbinder R, Jolley D, Wyatt M. Effects of a media campaign on back pain beliefs and its potential influence on management of low-back pain in general practice. Spine. 2001;26:2535-42.

Received for publication: 25 April 2005 